\title{
Nutrition and ageing
}

\section{Screening for malnutrition in dwelling elderly}

\author{
Antoni Salvà ${ }^{1,2, *}$ and Guillem Pera ${ }^{3}$ \\ ${ }^{1}$ Programa Vida Als Anys, Àrea Sanitària, Servei Català de la Salut, Travessera de les Corts 131-159, E-08028 \\ Barcelona, Spain: ${ }^{2}$ Hospital Sant Jaume, Mataró, Spain: ${ }^{3}$ Unitat de Recerca de la Fundació del Consorci Sanitari \\ del Maresme 'Doctor Jaume Esperalba i Terrades', Mataró, Spain
}

\begin{abstract}
The health of elderly people is often affected by inadequate nutritional intake. Psychosocial determinants and the higher prevalence of acute and chronic illnesses are risk factors for nutritional deficiencies in the elderly. Nutritional assessment (NA) or nutritional risk screening must be an important element in care programmes for elderly people in the community and should be part of all geriatric assessment programmes.
\end{abstract}

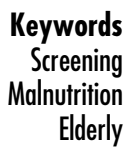

Studies on dietary intake of the elderly population show an average decrease in the intake of most nutrients with age. The recommended energy intake for the Spanish population aged over 70 years is $1700 \mathrm{kcal} \mathrm{day}^{-1}$ for women and $2100 \mathrm{kcal} \mathrm{day}^{-1}$ for men. According to recent nutritional surveys in Spain, above $25 \%$ of the noninstitutionalised aged population shows intakes lower than the reference values ${ }^{1-4}$. The percentage of people with inadequate intakes is considerably higher among people with functional dependence and greater comorbidity. Elderly people who live in good health in the community show low rates of undernutrition. In the SENECA study in Betanzos, Spain ${ }^{1}$, none of the subjects was found to have serum albumin level below $30 \mathrm{~g} \mathrm{l}^{-1}$ and only $3 \%$ had a body mass index (BMI) lower than $20 \mathrm{~kg} \mathrm{~m}^{-2}$. However, inadequate intakes for vitamin $\mathrm{B}_{6}$ and $\mathrm{B}_{12}$, carotenes, vitamin $\mathrm{D}$ and folic acid were found. In the Nutrition Survey of the Catalan population ${ }^{2}$, only $2.6 \%$ in the age group 65-75 years had a BMI lower than $20 \mathrm{~kg} \mathrm{~m}^{-2}$. In a study in Mataró (Cataluña) on a random sample of self-dependent people, only $1.5 \%$ had BMI values below $21 \mathrm{~kg} \mathrm{~m}^{-2}$ and $5 \%$ lower than $23 \mathrm{~kg} \mathrm{~m}^{-2}$ (unpublished data). In the same population group, using the Mini Nutitional Assessment (MNA) as the evaluation method, only $0.5 \%$ were classified in the undernutrition group and $9.5 \%$ had nutritional risk criteria ${ }^{5}$. Studying ill people with moderate to high levels of dependency for daily life activities (DLA), the percentage of undernutrition is much more important. In a study carried out in Canada on dependent people, Payette et al. ${ }^{6}$ found that $40 \%$ of men and $32 \%$ of women were underweight.

Undernutrition rates among the institutionalised elderly show high variability in different studies, ranging from 15 to $60 \%$ depending on the method used and characteristics of the subjects studied ${ }^{7-9}$.

\section{Risk factors for malnutrition in elderly people}

Different situations and factors can lead to decreased intake and undernutrition. They can be classified into two main groups ${ }^{10}$, as follows.

\section{Problems related to the environment}

In the Mataró study, $48.7 \%$ of people under 70 years of age were able to do their shopping independently, but this figure decreased to $22 \%$ for people over 80 years. Although $55 \%$ of this group of elderly people had some help in preparing their meals, $20.1 \%$ of over 65's and $31.6 \%$ of those over 80 years used to eat alone ${ }^{4}$. People living alone or eating alone usually eat less than people of the same age sharing their meals with others. They also tend to choose easy-to-prepare meals and to limit the range of different foods, thus increasing the chance for nutrient deficiencies. Poor presentation, poorly adapted or tasteless preparations are some other factors to be considered. Finally, restrictive diets can also cause a decrease in intake.

\section{Physical or psychological problems}

The use of chronic pharmacological treatments and polypharmacy increase the risk of interactions between drugs and nutrients. Among others, it is noteworthy to mention delayed drug absorption (iron salts, tetracycline, amoxycillin, ampicilline, cephalosporins, calcium, flufenacin, haloperidol); increased absorption of the drug (diazepam, lithium salts); and interference in nutrient 
absorption (antacids, paraffin oil, biguanides, hydracids). Drugs can also produce anorexia (diuretics, diltiazem, digoxin, fluoxetin, chlorpromazine, haloperidol, sedatives, cytostatics), and decreased taste (captopril, enalapril, amiloride, propanolol, hydrochlorothiazide, spironolactone, nifedipine, diltiazem, non-oestroidal anti-inflammatories), smell and swallowing capacity. Finally, some of them can produce digestive problems (digitalis drugs, opiates, non-oestroidal anti-inflammatories, L-DOPA, sulphonamides).

Dysphagia is common among people with cognitive impairment or as a consequence of stroke or cerebralvascular disease. Lesions in the oral cavity, which cause pain and/or the selection of foods, cause decrease in intake and therefore weight loss. People with physical dependence for feeding need family or carers to prepare their meals and to feed them.

Depression has been correlated with weight loss in many studies. People with Alzheimer's disease lose more weight than other people of the same age without dementia. There are several factors that can influence this, among which are upsetting of feeding behaviour and dependency on being fed.

Infections are also risk factors for undernutrition, apart from stimulating the production of cytokines that cause anorexia and blockage in the synthesis of hepatic albumin. Likewise, reduction in the immune capacity is one of the most important consequences of undernutrition, which, again, increases susceptibility for infections. Other illnesses are related to weight loss as well, such as neoplasia, hyperthyroidism, chronic obstructive lung disease, neurological diseases, visual handicap and alcoholism.

\section{Nutritional screening}

Nutritional screening (NS) is the process addressed to early identification of subjects with nutritional problems or those nutritionally at risk. The target group for nutritional screening are people at risk of nutritional problems or under poor nutritional status, in order to provide early intervention. Undernutrition is an appropriate condition for early detection by broad screening methods for the following reasons: (1) it is a public health problem owing to its magnitude and relevant consequences both in terms of health impact and costs; (2) it is sensitive and easy-to-apply screening methods are readily available; and (3) intervention strategies and therapeutic possibilities exist.

Nutrition intervention strategies are aimed to correct or counteract risk factors and to improve nutritional status, by means of either dietary counselling or nutritional support with adequately prescribed diets, nutritional supplements, tube or parenteral nutrition, as required. Nutritional support is particularly important in population groups where dietary inadequacy is due to chronic or

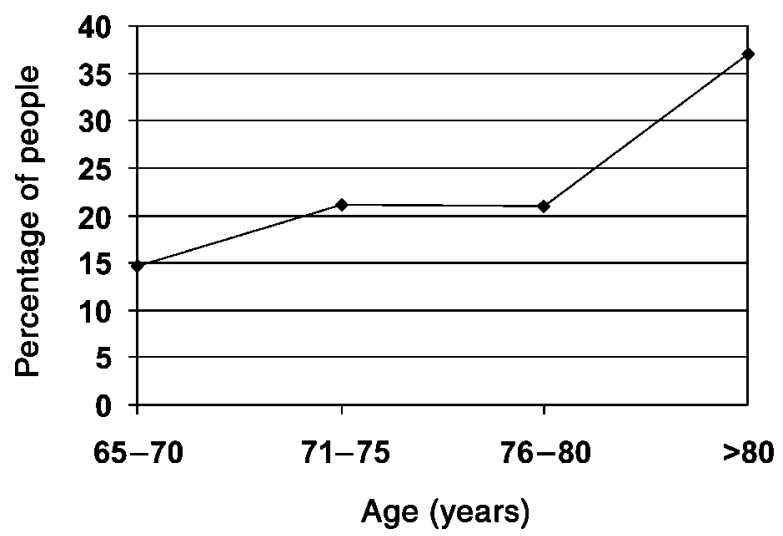

Fig. 1 Percentage of people who underwent more than $4 \%$ weight loss in one year of follow-up by age $(P=0.002)$

acute illnesses with treatable or preventable nutritional consequences.

In a longitudinal study, Wallace found that $13 \%$ of people over 65 years lost $4 \%$ of body weight over one year. This group had poorer health status and higher mortality $^{11}$. Preliminary data from a population-based, prospective observational study in Mataró, on a cohort of 391 community-dwelling people over 65 years old (people who could not walk excluded), showed that during the first year of follow-up $21.2 \%$ of subjects lost more than $4 \%$ of body weight, the proportion increasing with age $(P=0.002)$ (Fig. 1$)$. For the purpose of this study, frail elderly were defined either as people with difficulties carrying out daily life activities, measured by Lawton test, or people with more than two failures in the Pfeiffer cognitive test. The percentage of people suffering weight loss was significantly higher in the frail group compared with the vigorous $(P=0.005)$. Other studies on aged people with a good autonomy level, such as the Ageing Process Study of New Mexico, found that weight remained relatively stable during nine years of follow$u^{12}$. This evidence highlights frail elderly people with more frequent co-morbidity and handicaps for daily life activities as a target population for nutritional screening.

Our proposal for NS consists of a two-level scheme that can be applied according to the characteristics of the population (Fig. 2).

The first level of NS must be based on the analysis of relevant risk factors and either body weight or BMI. There are sensible, easy-to-use instruments useful at this level, such as the nutritional risk questionnaire 'Nutrition Screening Initiative'. This screening tool consists of 10 sections, four of which deal with social or environmental aspects: low consumption of milk products, fruit and vegetables; economic disadvantage or lack of sufficient money to buy food; usually having meals alone and being physically handicapped for shopping; cooking and eating on one's own ${ }^{13}$.

The shortened version of the Mini Nutritional Assessment is also useful at this stage. This is derived from the 


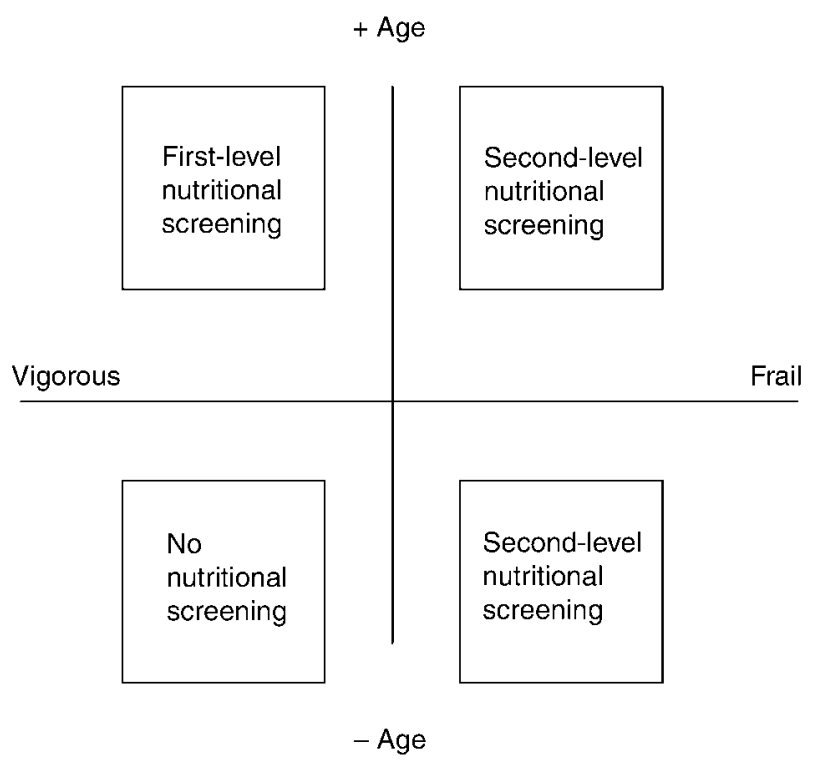

Fig. 2 Nutritional screening scheme. Among the high-risk population, a second-level evaluation is desirable whenever possible

MNA and the following items are included: BMI, weight loss, mobility, presence of depression or dementia, recent acute illnesses and loss of appetite (Fig. 3) ${ }^{14}$.

The relationship between BMI and mortality is well established. A BMI value below $21 \mathrm{~kg} \mathrm{~m}^{-2}$ is considered a sign of undernutrition. However, there is no unanimous agreement over the best cut-off point for elderly people. BMI above $23 \mathrm{~kg} \mathrm{~m}^{-2}$ for men and $24 \mathrm{~kg} \mathrm{~m}^{-2}$ for women seems to have the best correlation to survival ${ }^{15}$ and is therefore considered a cut-off point for this first level to indicate a more detailed evaluation. For people who

\section{Score $0-14:<11$, at risk $; \geqslant 11$, no risk of under nutrition.}

\section{6-ITEM MNA-SF}

\section{Body mass index (BMI) (weight-kg/height- $\mathrm{m}^{2}$ ): $<19=0,19-20.9=1,21-22.9=2,23+=3$}

\section{Recent weight loss (< 3 months)?} $>3 \mathrm{~kg}=0$, don't know = 1, 1-3 kg = 2, no weight loss $=3$

3. Acute disease or stress over the last 3 months? Yes $=0$, no $=2$

\section{Mobility:}

Bed $/$ chair $=0$, at home $=1$, can leave home $=2$

5. Dementia/depression: Severe $=0$, mild $=1$, no $=2$

\section{Loss of appetite over the last 3 months?} Severe lost $=0$, mild $=1$, no $=2$

Fig. 3 Shortened version of the Mini Nutritional Assessment cannot stand up, knee-height can be used to estimate height $^{16}$.

Weight loss greater than $10 \%$ within a 6 -month period has been considered an indicator for undernutrition. However, other studies - such as that by Wallace mentioned above suggest that even a $4 \%$ weight loss can have negative consequences for elderly people and therefore this group would also deserve further assessment.

This first level of evaluation must enable identification of risk situations candidate for appropriate advice or other suitable interventions. It should also contribute to identify people whose nutritional status requires further investigation and maybe a more specialised nutritional support programme.

The second level of $N A$ includes the following.

1. Evaluation of secondary clinical signs of malnutrition, an important element although often unspecific and late in manifestation.

2. Detailed food consumption assessment. This must include quantitative and qualitative data: number of meals a day, type of food and serving size, etc. Standard methods such as repeated 24-hour recall, food diaries or the diet history method are suitable for this purpose although their use is usually limited to dietitians and nutritionists. Description of food intake in a typical week can provide useful information, describing any food or beverage consumed from morning to night.

3. Body measurements: anthropometry provides valuable information in NA, particularly in the diagnosis of protein-calorie malnutrition. Body composition and its main compartments can be indirectly quantified ${ }^{17,18}$. It is a simple, safe, cheap and practical method, although not as precise as more sophisticated techniques. Body fat mass can be estimated by different site skinfold measurements using adequate regression equations. Muscular areas are valid indicators of body protein compartment and fat-free mass; these are calculated on the basis of different site skinfold measurements and limb circumferences by means of appropriate equations. Standardised procedures for anthropometric measurements should be followed in order to increase validity and reliability of body measurements, which can be compared with epidemiological and reference data. Measurements must be done on the right side, although limb amputations and other reasons can justify having measurements on the left side. Evaluation and interpretation of results can be obtained by comparisons with population-specific reference data ${ }^{19}$.

Biochemical parameters can help to classify the type and severity of malnutrition. Several conditions such as inflammation and renal and hepatic diseases among other factors can modify biochemical indicators.

Albumin is the most widely used indicator in clinical practice. Many studies have observed a correlation between serum albumin levels and length of hospital 
stay or early death. We must consider the dilution effect (of up to a maximum of $0.5 \mathrm{mg} \mathrm{dl}^{-1}$ ) due to an increase in intravascular volume associated with being bed-ridden. On the other hand, acute illness or inflammation causes a rapid decrease in albumin levels by the production of cytokines, which inhibit synthesis of albumin and facilitate albumin migration from intravascular to extravascular space. Albumin level below $3.5 \mathrm{mg} \mathrm{dl}^{-1}$, or particularly lower than $3.0 \mathrm{mg} \mathrm{dl}^{-1}$, is a favourable prognostic factor for mortality and morbidity in elderly people. Other proteins used are prealbumin, similar to albumin but with an average life span of 2-3 days (normal values of 0.20 to $0.40 \mathrm{~g} \mathrm{l}^{-1}$ ); transferrin, with an average life span of 8 days but highly dependent on iron levels - this fact should be considered, since iron deficiency is a frequent condition in old ill people (normal values range between 1.5 and $3.5 \mathrm{~g} \mathrm{l}^{-1}$ ); and retinol binding protein (RBP), with an average life of $12 \mathrm{~h}$ and normal values of less than $15 \mathrm{mg} \mathrm{l}^{-1}$.

Other instruments developed to objectively estimate risk of malnutrition and to facilitate intervention programmes such as the MNA can also be used in this second level. The MNA has been validated for the geriatric population and can be used in outpatient clinics 9,20 . This screening tool includes: anthropometric measurements (BMI, weight loss, mid-calf circumference), environmental risk factors, diet questionnaires and some items related to perceived health. The highest score is 30 points and the normal is above 23.5. Scores below 17 are considered as malnutrition while scores in the middle indicate nutritional risk. It is relatively simple, fast and easy-to-use. Other combined methods have been mainly used in surgical patients such as the Nutritional Prognosis Index $(\mathrm{NPI})^{21}$ or the Subjective Global Evaluation ${ }^{22}$.

In conclusion, the frequency of nutritional risk situations and weight loss in elderly people, as well as the possibility for early intervention, proves first-level NA to be cost-effective. It is advisable to incorporate a first-level NA in systematic screening strategies for elderly people, particularly those considered frail elderly, i.e. with greater co-morbidity and handicapped for daily life activities. An in-depth or second-level NA must be practised whenever nutritional risk criteria or malnutrition are present.

\section{References}

1 Moreiras O, Carbajal A, Perea I, Varela-Moreiras G, Ruiz Roso B. Nutrición y salud de las personas de edad avanzada en Europa: Euronut-Seneca. Estudio en España. Rev. Esp. Geriatr. Gerontol. 1993; 28(4): 197-242.

2 Serra Majem L, Ribas Barba L, García Closas R, et al. Avaluació de l'Estat Nutricional de la Població Catalana (1992-93). Avalauació dels Hàbits Alimentaris, el Consum d'Aliments, Energia $i$ Nutrients, $i$ de l'Estat Nutricional Mitjançant Indicadors Bioquímics i Antropomêtrics. Barcelona: Generalitat de Catalunya, Departament de Sanitat i Seguretat Social, 1996.

3 Fernandez-Ballart J, Gordillo BJ, Arija V, Martí-Henenberg
C. Consumo, hábitos alimentarios y estado nutricional de la población de Reus. La dieta y el equilibrio nutricional en los mayores de 60 años. Rev. Clin. Esp. 1989; 185: 282-92.

4 Salvà $\mathrm{A}$, Bolibar I, Bleda MJ. Hábitos dietéticos en una población de personas mayores que viven en la comunidad. Rev. Esp. Geriatr. Gerontol. 1998; 33(S1): 31 [abstract].

5 Salvà A, Bolibar I, Bleda MJ. MNA in clinical practice. In: Vellas B, Garry PJ, Guigoz Y, eds. Mini Nutritional Assessment (MNA): Research and Practice in the Elderly. Basel: Karger, 1999; 35-46.

6 Payette H, Gray-Donald K, Cyr R, Boultier V. Predictors of dietary intake in a functionally dependent elderly population in the community. Am. J. Public Health 1995; 85(5): 677-83.

7 Morley JE, Jai A. Nutritional issues in nursing home care. Ann. Intern. Med. 1995; 123: 850-9.

8 Lipski PS, Torrance A, Kelly PJ, James OFW. A study of nutritional deficits of long stay geriatric patients. Age and Ageing 1993; 22: 244-55.

9 Salvà A, Bolibar I, Muñoz M, Sacristan V. Un nuevo instrumento para la valoración nutricional en geriatria: el Mini Nutritional Assessment (MNA). Rev. Gerontol. 1996; 6: 319-28.

10 Council for Nutritional Clinical Strategies in Long-Term Care. Nutritional Clinical Strategies in Long-Term Care. Anorexia in the Elderly. Council for Nutritional Clinical Strategies in Long-Term Care Special Report. Princeton Meadows: Multimedia Health Care, 1999.

11 Wallace JI. Involuntary weight loss in older outpatients: incidence and clinical significance. J. Am. Geriatr. Soc. 1995; 43(4): 329-37.

12 Vellas BJ, Albarede JL, Garry PJ. Diseases and aging: patterns of morbidity with age; relationship between aging and age-associated diseases. Am. J. Clin. Nutr. 1992; 55: $1225 \mathrm{~S}-30 \mathrm{~S}$.

13 Posner BM, Jette AM, Smith KW, Miller DR. Nutrition and health risks in the elderly: The Nutrition Screening Initiative. Am. J. Public Health 1993; 83: 972-8.

14 Rubenstein LZ, Harker JO, Salvà A, Vellas B. Nutritional screening in geriatric practice: developing the Short-Form Mini-Nutritional Assessment (MNA-SF). J. Gerontol. 2001; 56A(6): 366-72.

15 Beck AM, Ovesen L. At which body mass index and degree of weight loss should hospitalized elderly patients be considered at nutritional risk? Clin. Nutr. 1998; 17(5): 195-8.

16 Chumlea WC, Guo SS. Equations for predicting stature in white and black elderly individuals. J. Gerontol. 1992; 47: M197-203.

17 Chumlea WC, Guo SS, Vellas B. Assessment of proteincalorie nutrition. In: Kopple JD, Massry SG, eds. Nutrition Management of Renal Disease. Media, PA: Williams \& Wilkins, 1991; 203-28.

18 Valtueña S, Arija V, Salas-Salvadó J. Estado actual de los métodos de evaluación de la composición corporal: descripción, reproducibilidad, precisión, ámbitos de aplicación, seguridad, coste y perspectivas de futuro. Med. Clin. (Barc.) 1996; 106: 624-35.

19 Esquius M, Schwartz S, López Hellin J, Andreu AL, García E. Parámetros antropométricos de referencia de la población anciana. Med. Clin. (Barc.) 1993; 100: 692-8.

20 Guigoz Y, Vellas B, Garry PJ. Mini Nutritional Assessment: a practical assessment tool for grading the nutritional state of elderly patients. Facts Res. Gerontol. 1994; (Suppl. 2): 15-59.

21 Mullen JL, Buzby GP, Waldman MT, Gertner MH, Hobbs CL, Rosato EF. Prediction of operative morbidity and mortality by preoperative nutritional assessment. Surg. Forum 1979; 30: $80-2$.

22 Ulander K, Grahn G, Jeppsson B. Subjective assessment of the nutritional status. Validity and reliability of a modified Detsky index in a Swedish setting. Clin. Nutr. 1993; 12: 15-9. 